\title{
Water-soluble carbosilane dendrimers protect phosphorothioate oligonucleotides from binding to serum proteins
}

\author{
Louis Chonco, ${ }^{a}$ Jesus F. Bermejo-Martín, ${ }^{a}$ Paula Ortega, ${ }^{b}$ Dzmitry Shcharbin, ${ }^{d}$ Elzbieta Pedziwiatr, ${ }^{d}$ \\ Barbara Klajnert, ${ }^{d}$ F. Javier de la Mata, ${ }^{* b}$ Ramon Eritja, ${ }^{c}$ Rafael Gómez, ${ }^{* b}$ Maria Bryszewska ${ }^{* d}$ and \\ $M^{a}$ Angeles Muñoz-Fernandez ${ }^{* a}$
}

\author{
Received 16th March 2007, Accepted 27th April 2007 \\ First published as an Advance Article on the web 14th May 2007 \\ DOI: $10.1039 /$ b703989a
}

\begin{abstract}
Treatment of dendriplexes formed between water-soluble carbosilane dendrimers and phosphorothioate oligodeoxynucleotides (ODN) with the anionic detergent sodium dodecyl sulfate disrupted the complexes indicating that the nature of the union in such dendriplexes is merely electrostatic. However, dendriplexes were not dissociated by serum proteins like bovine or human serum albumins, as assessed by gel electrophoresis and fluorescence experiments. This would imply a dendrimer-mediated protective effect able to prevent ODN interactions with serum proteins and additionally could translate into a reduction of the ODN doses needed to achieve the biological effects. The employment of carbosilane dendrimers as carriers may solve the problem of ODN kidnapping by plasmatic proteins as a key drawback for therapeutics involving ODNs. As examples, transfection processes on normal primary peripheral blood cells and diagnosis of HIV infection in the presence of serum have been assayed.
\end{abstract}

\section{Introduction}

In the last few years, many anti-viral drugs have been developed to fight HIV infection, and proven to control infection. However, many phase II and III trials have reported severe side effects (i.e., liver toxicity), but particularly the emergence of drug-resistant strains. Moreover, all the current therapies do not reach all target cells (i.e., inside tissues and the central nervous system) and are not able to eradicate latently infected cells. ${ }^{1}$ The existence of viral reservoirs makes viral eradication nearly impossible with the drugs available to date. All of this makes necessary the development of new alternative therapeutic approaches to achieve better efficiency with less adverse effects. Gene therapy (GT) represents one of those new therapeutic approaches. However, GT is undergoing some troubles due to the problems that viral vectors present as vehicles for delivery of nucleic acids. ${ }^{2}$ For instance, the use of viral vectors suffers from adverse effects, such as immune reaction against the viral vector or lymphoproliferative syndromes associated with oncogene deregulation. Besides, the consequences of the incorporation of non-human genetic material into human cells are still difficult to predict. An additional problem is the oligonucleotides' tendency to bind non-specifically to serum proteins that decreases their bioavailability, making necessary higher doses for accomplishing a desired therapeutic effect. In some cases, such non-specific binding to proteins can induce toxic effects,

${ }^{a}$ Laboratorio de Inmunobiología Molecular, Hospital General Universitario Gregorio Marañón, Madrid, Spain

${ }^{b}$ Departamento de Química Inorgánica, Universidad de Alcalá, Campus Universitario,E-28871, Alcalá de Henares, Spain.E-mail:Rafael.Gomez@ uah.es; Fax: (+34) 91 8854683; Tel: (+34) 918854685

'Instituto de Biología Molecular de Barcelona, CSIC, Jordi Girona, Barcelona, Spain

${ }^{d}$ Department of General Biophysics, University of Lódz, Lódz, 90-237, Poland especially for the phosphorothioate oligodeoxynucleotide (ODN) derivatives. ${ }^{3}$ Bovine serum albumin (BSA) and human serum albumin (HSA) bind ODNs, inducing their uptake by cells of the reticulo-endothelial system and not allowing them to reach the extravascular space. Serum protein binding to ODN avoids thus the overall interaction of oligonucleotides with cells. ${ }^{3 a, 4}$ Several other proteins also bind ODNs, and the physiological state of the cell influences the binding patterns. ${ }^{5}$ Some strategies have been proposed to avoid ODN binding to serum proteins, for instance, the use of vehicles such as cationic lipid carriers (lipoplexes) ${ }^{6}$ or dendrimers (dendriplexes). ${ }^{7}$ One of the crucial impediments for successful systemic ODN or DNA transfer with lipoplex exhibiting a positive global charge, seems to be their inactivation because of the non-specific binding of such liposomes with anionic serum proteins $^{8}$ as well as side-effects like lung inflammatory reactions. ${ }^{9}$ Dendrimers emerge as an alternative approach to liposomes and polymeric systems for drug delivery. Their major advantages are the uniform structure, multiple sites of attachment and the versatility to modify their skeletons and surfaces, allowing a precise characterization of the interaction of dendrimer-drug. Potential transfecting agents based on PAMAM,${ }^{10}$ phosphoruscontaining $^{11}$ dendrimers or some small amphiphilic dendrimers ${ }^{12}$ have shown transfecting activity even in the presence of serum. Although several studies have been published concerning the interaction between PAMAM dendrimers and BSA, ${ }^{13}$ however, as far as we know, there is only one study reporting on the interaction between PAMAM-containing dendriplexes and serum proteins. ${ }^{14}$

Water-soluble carbosilane dendrimers containing ammonium or amine groups at their periphery have been recently described by our groups as biocompatible molecules with good perspectives as non-viral carriers for ODN. ${ }^{15}$ In this work, we describe the interactions between albumin and the dendriplexes formed between ODN and second generation carbosilane dendrimers having ammonium groups at their periphery (see Fig. 1) by gel 

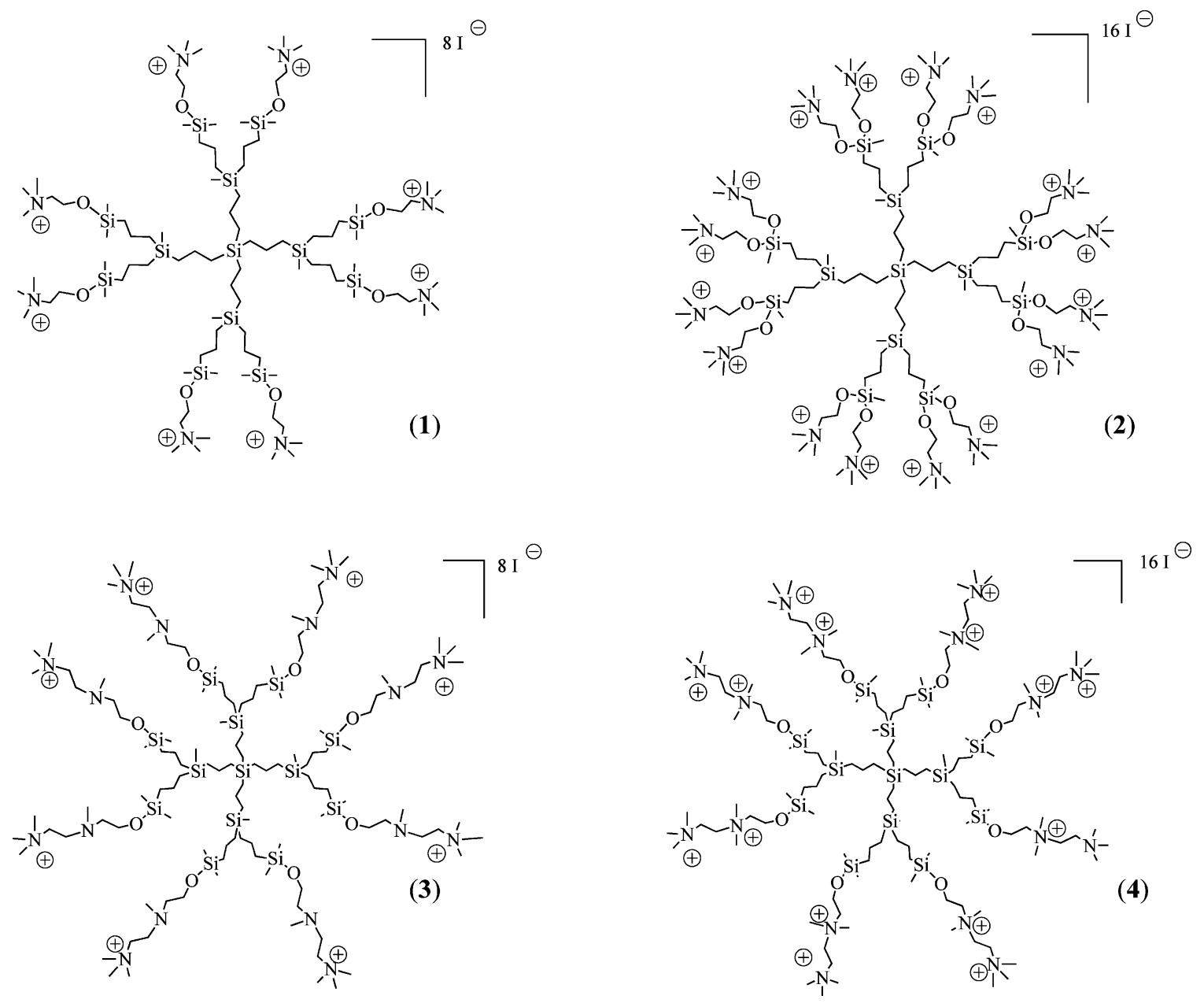

Fig. 1 Molecular representation of the ammonium-terminated carbosilane dendrimers 1-4.

electrophoresis and fluorescence spectroscopy. Here we prove a dendrimer-mediated protection of ODNs from binding to serum proteins to evaluate their use in some biomedical applications for HIV infection research.

\section{Results and discussion}

We have published that second generation ammonium-terminated carbosilane dendrimers have shown good toxicity profiles in PBMCs primary cell culture models and erythrocytes over extended periods, employing different approaches such as evaluation of cell membrane integrity, metabolic activity, apoptosis induction, cellular morphology, and cell mobility. ${ }^{15 b}$ In addition, the existence of $\mathrm{Si}-\mathrm{O}$ bonds in their architecture opens the way to use them as drug delivery system by means of the corresponding hydrolytic process. Dendrimers $2 \mathrm{G}-\left[\mathrm{Si}\left(\mathrm{OCH}_{2}-\right.\right.$ $\left.\left.\mathrm{CH}_{2} \mathrm{NMe}_{3}{ }^{+} \mathrm{I}^{-}\right)\right]_{8}$ (1), 2G-[Si( $\left.\left(\mathrm{OCH}_{2} \mathrm{CH}_{2} \mathrm{NMe}_{3}{ }^{+} \mathrm{I}^{-}\right)_{2}\right]_{8}$ (2) and 2G$\left[\mathrm{Si}\left\{\mathrm{O}\left(\mathrm{CH}_{2}\right)_{2} \mathrm{~N}(\mathrm{Me})\left(\mathrm{CH}_{2}\right)_{2} \mathrm{NMe}_{3}{ }^{+} \mathrm{I}^{-}\right\}\right]_{8}$ (3) were prepared according to the reported methods. ${ }^{15}$ Dendrimer $2 \mathrm{G}-\left[\mathrm{Si}\left\{\mathrm{O}\left(\mathrm{CH}_{2}\right)_{2}\right.\right.$ $\left.\left.\mathrm{N}(\mathrm{Me})_{2}{ }^{+}\left(\mathrm{CH}_{2}\right)_{2} \mathrm{NMe}_{3}{ }^{+}\left(\mathrm{I}^{-}\right)_{2}\right\}\right]_{8}$ (4) containing 8 groups of doubled methylated outer fragments was prepared by addition of 16 equivalents of $\mathrm{MeI}$ to the corresponding amine-terminated dendrimer $2 \mathrm{G}-\left[\mathrm{Si}\left\{\mathrm{O}\left(\mathrm{CH}_{2}\right)_{2} \mathrm{~N}(\mathrm{Me})\left(\mathrm{CH}_{2}\right)_{2} \mathrm{NMe}_{2}\right\}\right]_{8}{ }^{15}$ (see Experimental section). Dendrimer 4 exhibits similar toxicity profiles to those shown by dendrimer 3 . The structures of the all dendrimers used in this work are depicted in Fig. 1. First generation dendrimers were too water-sensitive for chemical evaluation while those of the third generation were not tested due to solubility problems. These features precluded data rationalization on the basis of different generations.

Dendriplexes were prepared as published elsewhere. ${ }^{15 b}$ Phosphorothioate ODNs used for binding studies were PPT and TAR, 15 or 16 bases in length respectively (see Experimental section) and both ODNs showed identical behaviour. The interaction of the dendriplexes, formed by dendrimers 1-4 and ODNs, with BSA has been studied by agarose gel electrophoresis showing no dissociation of the complexes in any case as is shown in Fig. 2. For a more detailed study, dendriplex 3-ODN was chosen as an example. The interactions of dendriplex 3-ODN with BSA and with the anionic detergent sodium dodecyl sulfate (SDS) have been studied by electrophoresis (see Fig. 3). The electrophoregram showed different patterns of migration depending on the agent used. ODN migration was retarded in the presence of BSA (see entry 9) as indirect evidence of the formation of a complex between ODN and proteins. The ODN migration pattern was also altered in the presence of dendrimer 3 (entry 1) due to the formation of a complex between the cationic dendrimer and the anionic ODN as had been expected. ${ }^{13}$ Interestingly, when the dendriplexes 

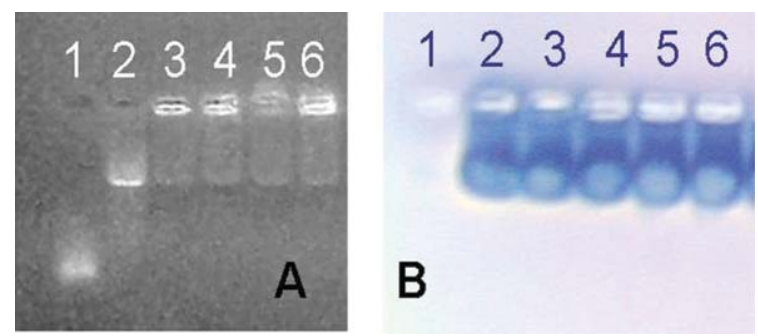

Fig. 2 (A) Electrophoresis on a 3\% agarose gel (stained with ethidium bromide) of dendriplex formed by different carbosilane dendrimers and TAR ODN in a ratio (+)-(-) $2: 1$ in the presence of increasing concentrations of BSA. (B) The same gel stained with Blue Paragon showing the protein migration. (1) ODN; (2) ODN + $10 \% \mathrm{BSA}$; (3) $1-\mathrm{ODN}+10 \% \mathrm{BSA}$; (4) $3-\mathrm{ODN}+10 \% \mathrm{BSA}$; (5) $2-\mathrm{ODN}+10 \%$ BSA; (6) $4-\mathrm{ODN}+10 \%$ BSA.
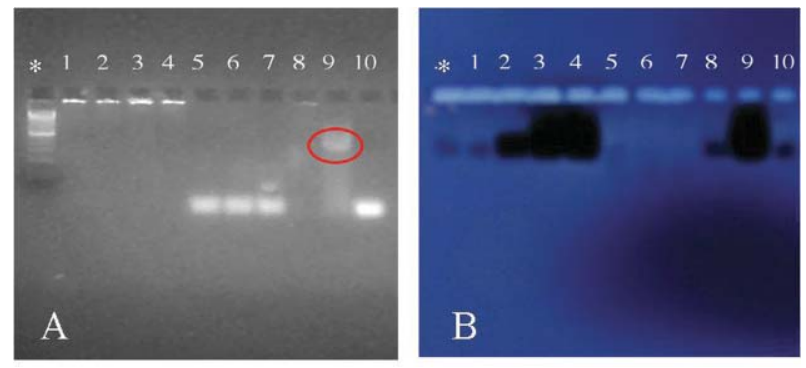

Fig. 3 (A) Electrophoresis on a 3\% agarose gel (stained with ethidium bromide) of dendrimer 3, ODN (TAR) or dendriplex 3-ODN in a ratio (+)-(-) $2: 1$ in the absence or presence of increasing concentrations of BSA or SDS. (B) The same gel stained with Blue Paragon showing the protein migration. * denotes $100 \mathrm{bp}$ DNA ladder as reference; (1) 3-ODN; (2) $3-\mathrm{ODN}+2 \% \mathrm{BSA}$; (3) $3-\mathrm{ODN}+5 \% \mathrm{BSA}$; (4) 3-ODN + 10\% BSA; (5) $3-\mathrm{ODN}+0.5 \% \mathrm{SDS}$; (6) $3-\mathrm{ODN}+1 \% \mathrm{SDS}$; (7) $3-\mathrm{ODN}+2 \% \mathrm{SDS}$; (8) 3-ODN + RPMI 1640 supplemented with serum (10\% FCS); (9) $\mathrm{ODN}+10 \% \mathrm{BSA}$; (10) ODN.

3-ODN were challenged with increasing concentrations of BSA, no changes in this migratory pattern were found (see entries 2-4) proving that under these conditions, BSA was not able to dissociate the complex. However, the treatment with SDS in all the tested concentrations disrupted the complex, allowing the ODN to be electrophoresed and analyzed by its mobility in the gel (entries $5-7$ ), also indicating that the nature of the complex union is based on electrostatic interactions.

Further studies were conducted to evaluate ODN interactions with proteins of $A B$ human serum when the ODNs were naked or alternatively complexed with dendrimers. Fig. 4 shows the results of interactions between ODN and proteins of human serum. Entries 2-4 clearly show the half migration of the ODN in the presence of human $\mathrm{AB}$ serum with respect to the ODN alone (entry 5). These results reveal the ODN union to human serum proteins, which is confirmed by the migration pattern of the proteins (see Fig. 4B): proteins and ODN migrated at the same level. Regarding the dendriplex 3-ODN, this was incubated for $20 \mathrm{~min}$ prior to the addition of increasing amounts of serum (see Fig. 5). When the dendriplex 3-ODN was challenged with increasing concentrations of human $\mathrm{AB}$ serum, no changes in this migratory pattern were found. ODN did not migrate towards the positive pole (entries 3-5) and at the same time, the pattern of

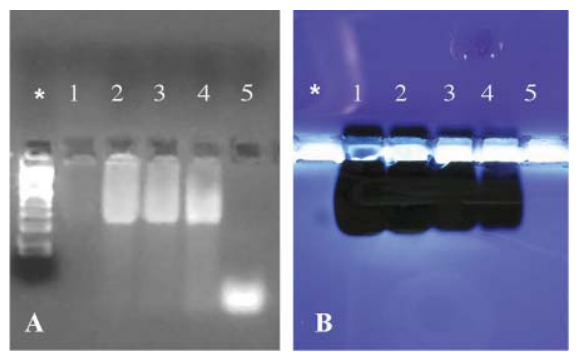

Fig. 4 (A) Electrophoresis on a 3\% agarose gel (stained with ethidium bromide) of ODN (TAR) in the absence or presence of increasing concentrations of AB human serum. (B) The same gel stained with Blue Paragon showing the protein migration. * denotes 100 bp DNA ladder as reference; (1) $\mathrm{AB}$ human serum; (2) $\mathrm{ODN}+20 \% \mathrm{AB}$; (3) $\mathrm{ODN}+10 \% \mathrm{AB}$; (4) $\mathrm{ODN}+5 \% \mathrm{AB} ;(5) \mathrm{ODN}$.
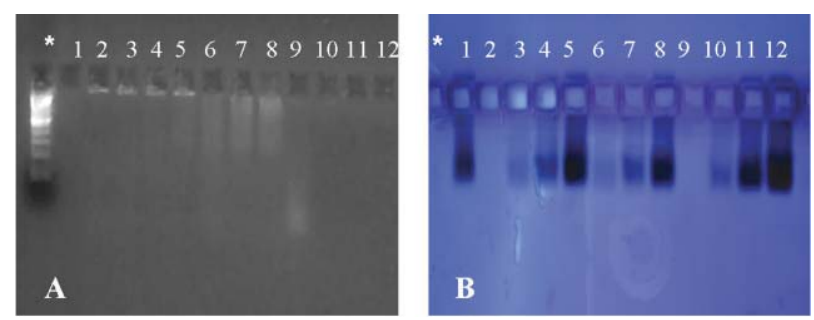

Fig. 5 (A) Electrophoresis on a 3\% agarose gel (stained with ethidium bromide) of dendrimer 3, ODN (PPT) or dendriplex 3-ODN in a ratio (+)-(-) $2: 1$ in the absence or presence of increasing concentrations of AB human serum. (B) The same gel stained with Blue Paragon showing the protein migration. * denotes 100 bp DNA ladder as reference; (1) $20 \%$ $\mathrm{AB}$ human serum; (2) 3-ODN; (3) 3-ODN + 5\% AB; (4) 3-ODN + $10 \%$ $\mathrm{AB}$; (5) 3-ODN + 20\% $\mathrm{AB}$; (6) $\mathrm{ODN}+5 \% \mathrm{AB}$; (7) $\mathrm{ODN}+10 \% \mathrm{AB}$; (8) $\mathrm{ODN}+20 \% \mathrm{AB}$; (9) ODN; (10) $3+5 \% \mathrm{AB}$; (11) $3+10 \% \mathrm{AB}$; (12) $3+$ $20 \% \mathrm{AB}$.

protein migration was just the same as that displayed by proteins of the control (absence of ODN and dendrimer, entry 1) and the same as the one exhibited by proteins in the presence of ODN (entries 6-8) or dendrimers (entries 10-12). These features indicate again a protective effect of the dendrimer towards ODN from binding to serum proteins. Only in the dendriplex challenged with $20 \%$ of total serum (entry 5), a slight change in the ODN migration was observed: most of the ODN did not migrate but a small part did, to an intermediate position, similar to the pattern shown for ODN in the presence of serum (entries 6-8). This could be a consequence of the competition between dendrimer and serum proteins for the ODN, resulting partially in ODN releasing from the ODN-dendrimer complex and further formation of the ODNprotein complex when a high concentration of proteins is present in the medium. Finally, dendrimers without ODN did not change the migratory pattern of the proteins, evidencing no interactions between them, although a weak electrostatic interaction cannot be ruled out (vide infra). Serum albumin has a net negative charge but it is not uniformly charged within the structure and, at physiological $\mathrm{pH}$, domains I and II are negatively ionized while domain III is weakly positively charged. Hence, the ODN can interact with this domain III enabling the formation of a complex between albumin and ODN. In the case of ammonium-terminated dendrimers, they may theoretically interact with both domains I 
and II. The interacting ability of PAMAM with albumin has been reported ${ }^{13,16}$ and due to the low isoelectric point of albumin, it interacts better with low protonated dendrimers than with the highly protonated ones. The poor interaction of PAMAM with albumin may indicate that the less polar sites of the dendrimers are probably not accessible to the albumin hydrophobic residues, and the weak polar interactions between the albumin hydrophilic residues and the dendrimer surface would not allow any significant structural alteration of the dendrimer and albumin. Moreover, it has been published that the binding of the dendrimers with proteins mainly occurs when both electrostatic and hydrophobic interactions take place. ${ }^{16}$ Perhaps a similar behaviour is occurring in the case of the carbosilane dendrimer, showing a high charge surface along with a high degree of hydrophobicity inside. Finally, the electrostatic interaction between the ODN and the carbosilane dendrimers may prevent the interaction of the former with domain III of the albumin.

In this study, both types of ODNs showed similar results as mentioned. Although special attention was focused on detecting possible differences, no changes were observed as described. The presence of six guanines in the oligonucleotide against the PPT element could cause different behaviour compared with that of TAR, due to the possible formation of the G-tetrads. We believe that the PPT oligonucleotide is probably not forming a very stable quadruplex. All the guanines are at the $3^{\prime}$-end and are situated in a row, so in order to form a quadruplex, four strands are needed to bind each other to form an intermolecular quadruplex. This type of quadruplex has been described to be less stable than intramolecular quadruplexes. ${ }^{17}$ An oligonucleotide having the six guanines separated in two groups of 3 guanines by 1-3 nucleotides will form a very stable quadruplex and hence, a more stable bimolecular quadruplex may be formed.

Electrophoresis experiments were confirmed by spectrofluorimetric results. Since ODNs were labelled with fluorescein, it was possible to study changes in its rotational freedom in the presence of BSA or dendrimers and in the system dendriplex + BSA. Again the dendriplex 3-ODN has been elected as a representative example. The rest of the dendriplexes formed by dendrimers $\mathbf{1}$, $\mathbf{2}$ and $\mathbf{4}$ afforded analogous results and a more detailed physicochemical study will be published separately. ${ }^{18}$ The increase of the fluorescence polarization of fluorescein in the presence of dendrimers (Fig. 6A) or in the presence of BSA (Fig. 6B) indicates that ODNs were located in a more rigid environment. This is an indirect proof that ODNs created complexes with both dendrimers and BSA. However, it is worth mentioning that upon addition of dendrimers, the enhancement of polarization was bigger than after adding BSA. This may mean that the dendrimer-ODN union is stronger than that of the protein-ODN. Moreover, the process of forming complexes occurred at lower concentrations in the case of dendrimers. Therefore, a lower number of molecules of dendrimers were needed to complex ODN, compared to BSA. When ODN and dendrimer 3 were preincubated for 15 minutes in a charge ratio $(+)-(-) 5: 1$ at different concentrations and then the complexes were added to the BSA sample of constant concentration, no changes in the polarization of fluorescein (Fig. 6C) were observed. The value of the polarization equalled the level of the plateau from Fig. 6A. It means that the dendrimer-ODN complexes were stable and, additionally, they were not disrupted by the protein presence. Thus, this fact constitutes further evidence of the protective role of
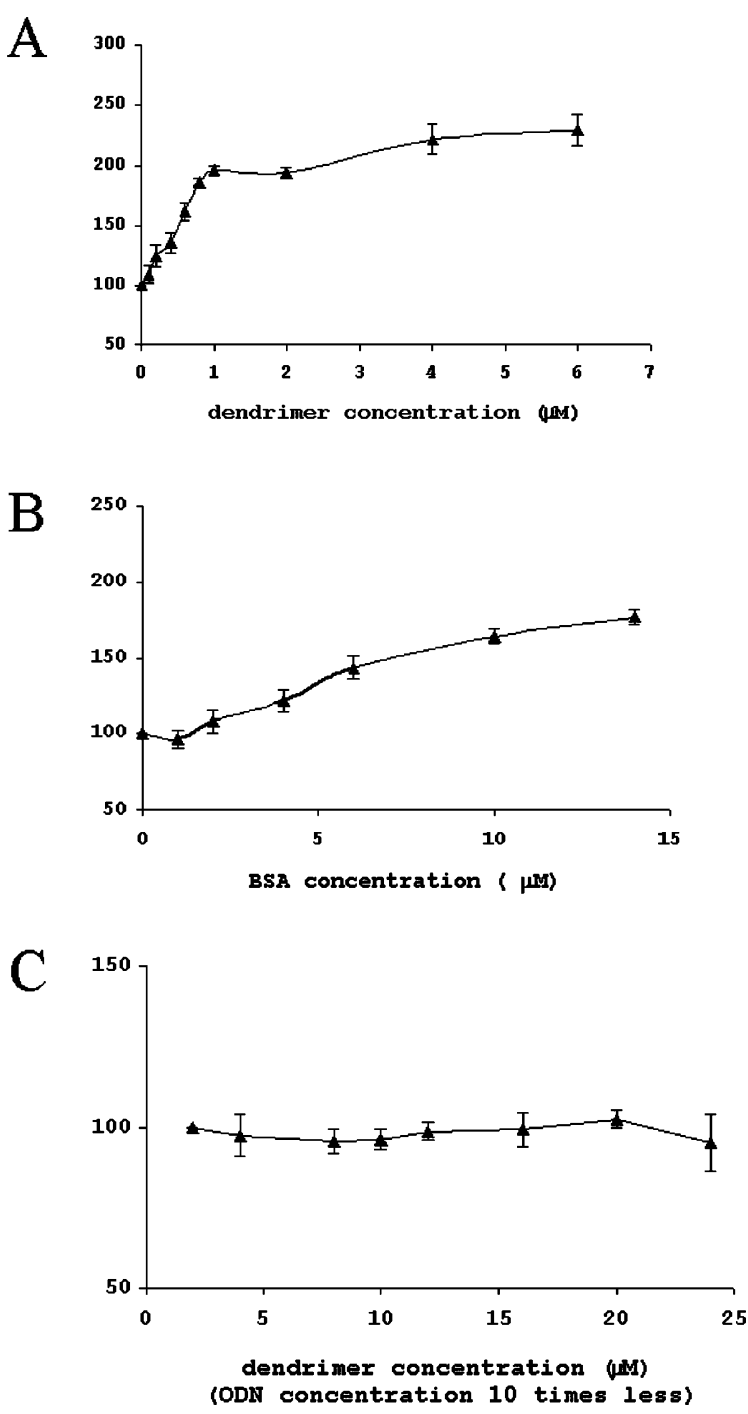

Fig. 6 (A) Changes in the polarization of labelled ODN (TAR) upon addition of dendrimer 3, $C_{\mathrm{ODN}}=0.1 \mu \mathrm{M}$. (B) Changes in the polarization of labelled ODN (TAR) upon addition of BSA, $C_{\mathrm{ODN}}=0.1 \mu \mathrm{M}$. (C) Changes in the polarization of labelled ODN (TAR) upon addition of complex 3-ODN (ratio (+)-(-) $5: 1$ ) to BSA at a constant concentration of $10 \mu \mathrm{M}$.

the carbosilane dendrimers for ODNs by preventing the formation of complexes between ODNs and serum albumin.

It is possible that weak electrostatic interactions between BSA and dendrimers can occur. In order to analyze them, BSA labelled with Alexa Fluor 488 (AF488) was used. We observed that dendrimer 3 quenched the fluorescence of AF488 that was attached to the surface of BSA (Fig. 7). Nevertheless, dendrimers were not able to change the intensity of intrinsic fluorescence of BSA (Fig. 7). It means that the environment of the two tryptophans remained unchanged. Quenching of AF488 fluorescence might occur via direct contact between the dendrimer and the fluorophore. However, no changes in the intrinsic fluorescence of BSA means that dendrimers did not cause any conformational disturbances within the protein molecule.

To confirm the protection effect described above, a preliminary biomedical study (toxicity, transfection and HIV inhibition assays) 


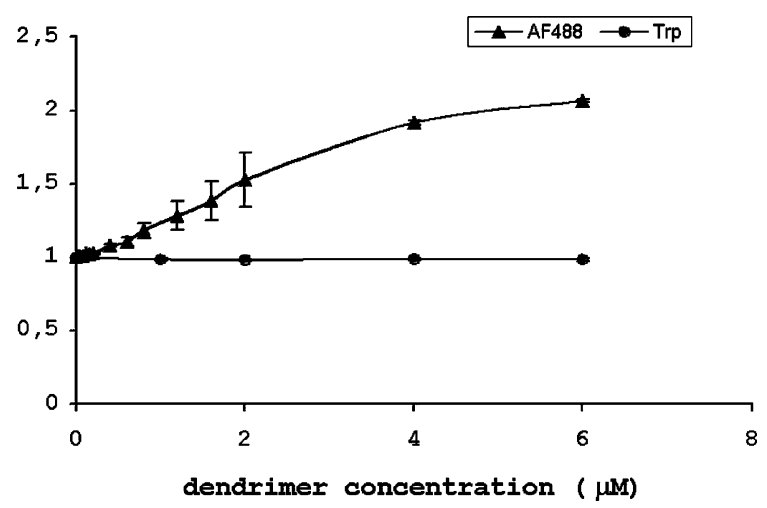

Fig. 7 Quenching of fluorescence of tryptophans $\left(C_{\mathrm{BSA}}=5 \mu \mathrm{M}\right)$ and AF488 $\left(C_{\mathrm{BSA}}=20 \mu \mathrm{M}\right)$ by dendrimer 3. $F_{0}$ - the initial fluorescence intensity, $F$ - the fluorescence intensity after adding dendrimer 3 .

of the use of dendriplexes in the presence of serum has been performed in order to evaluate its consequences. In this study, we have used dendrimers 3-4 and oligonucleotide sequences of different length (TAR, GEM91 and REV) as potential inhibitors of the HIV-1 virus (see Experimental section). The toxicity evaluation of dendrimers 3-4 has been carried out by means of MTT and LDH assays (see Fig. 8). For MTT, peripheral blood mononuclear cells (PBMCs) treated with $\mathbf{3}$ and $\mathbf{4}$ at $1 \mu \mathrm{M}$ in the presence of $10 \%$ of fetal calf serum (FCS) at 18 and $36 \mathrm{~h}$ presented similar
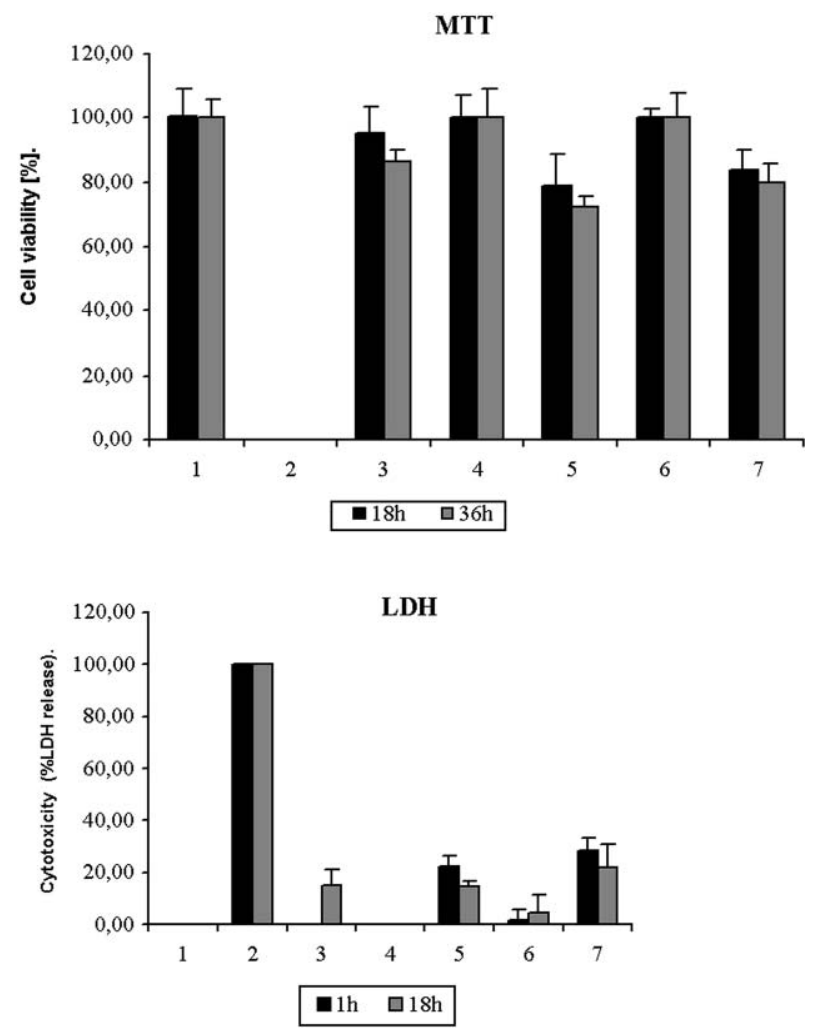

Fig. 8 (A) MTT assay at different times; (1) control; (2) DMSO 15\%; (3) dextran $5 \mu \mathrm{M}$; (4) dendrimer 3, $1 \mu \mathrm{M}$; (5) dendrimer 3, $5 \mu \mathrm{M}$; (6) dendrimer 4, $1 \mu \mathrm{M}$; (7) dendrimer 4, $5 \mu \mathrm{M}$. (B) LDH assay at different times; (1) control; (2) triton $\mathrm{x}-100,0.5 \%$; (3) dextran $5 \mu \mathrm{M}$; (4) dendrimer $3,1 \mu \mathrm{M}$; (5) dendrimer 3, $5 \mu \mathrm{M}$; (6) dendrimer 4, $1 \mu \mathrm{M}$; (7) dendrimer 4, $5 \mu \mathrm{M}$. mitochondrial activities (MA) to the control. However, toxicities were increased around $20 \%$ when concentration was raised to $5 \mu \mathrm{M}$. In another toxicity approach, cell membrane damage was measured by a lactate dehydrogenase (LDH) cytotoxicity assay. Two different concentrations ( 1 and $5 \mu \mathrm{M}$ ) were tested over 1 and $18 \mathrm{~h}$ exposure. At the lower concentration, dendrimers 3-4 did not induce significance LDH release $(<5 \%)$. However, a $20 \%$ increase of membrane damage was observed at $5 \mu \mathrm{M}$. To sum up, both assays indicate the lack of toxicity of the dendrimers in the presence of serum below $5 \mu \mathrm{M}$ concentration.

Transfection of the dendriplex formed by $\mathbf{4}$ and fluoresceinated ODN (TAR) in PBMCs with a RPMI culture medium containing $10 \%$ of FCS was performed by confocal microscopy. Fig. 9 shows internalization and intracellular distribution of the ODN, illustrating that the dendriplex is not deactivated before the internalization process.
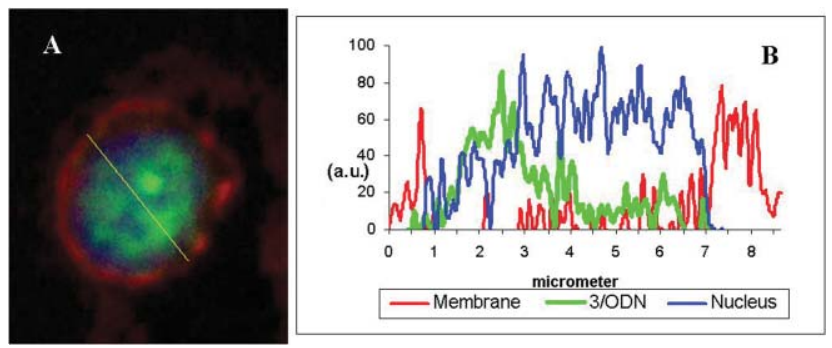

Fig. 9 (A) Confocal projection of six images of a representative $\mathrm{T}$ lymphocyte incubated with 3-ODN-FITC (TAR) dendriplex (green) for $24 \mathrm{~h}$. The plasma membrane and the nucleus are stained with CD45 (red) and DAPI (blue), respectively. (B) Intensity profile along the depicted line in $\mathbf{A}$ (yellow). Note that most of $\mathbf{3}-\mathrm{ODN}$ is accumulated inside the nucleus.

Finally, HIV-1 inhibition assays using dendrimers 3-4 and the corresponding dendriplexes formed with single ODNs or cocktails (see Experimental section) were determined via ELISA through the evaluation of the p24 antigen release into culture supernatants of MT-2 and PBMCs (see Fig. 10). Dendrimers by themselves were not able to inhibit infection against HIV-1 (data not shown). With respect to the MT-2 cell, higher inhibitions were found when dendriplexes 4-ODN (TAR, 45\%), 4-ODN (cocktail 1, 25\%) and 4-ODN (cocktail 2, 53\%) were used compared to ODNs alone (see Fig. 10A). All these dendriplexes did not cause significance LDH release $(<10 \%)$ (see Fig. 10B) indicating that the dendrimer increases the inhibition efficiency without increasing toxicity in the presence of $10 \%$ of FCS. Analogous results have been observed in primary lines as PBMCs, more representative of physiological systems and at the same time less resistant to in vitro treatment. For instance, increased inhibition was found in the systems 3ODN (TAR, 18\%) or 4-ODN (cocktail 1, 43\%) with respect to those observed for the ODN alone, both in the presence of serum (Fig. 10C and D respectively). All these features are consistent with a protective effect of the carbosilane dendrimers on the ODN action in the presence of serum. It is worth noting from Fig. 10C that inhibition was similar with the three sequences (antisense, sense, random), showing a diminution of around $1 / 3$ in the p24 levels with respect to the control of infected non-treated cells. Thus, the inhibitory effects were due to non-sequence specific effects, as described previously. ${ }^{19}$ However, the results observed in 


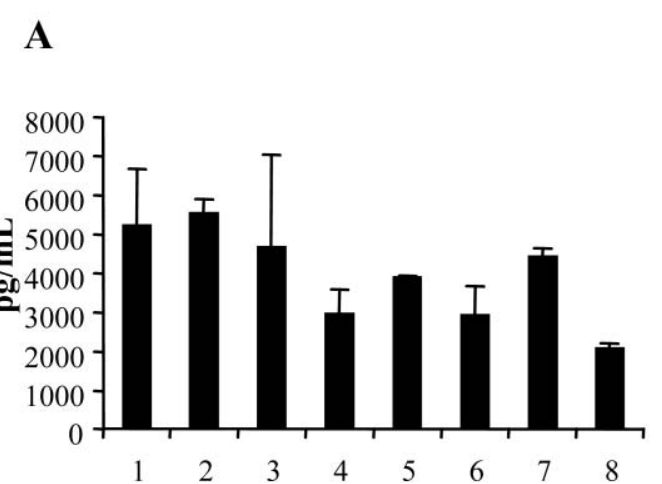

C

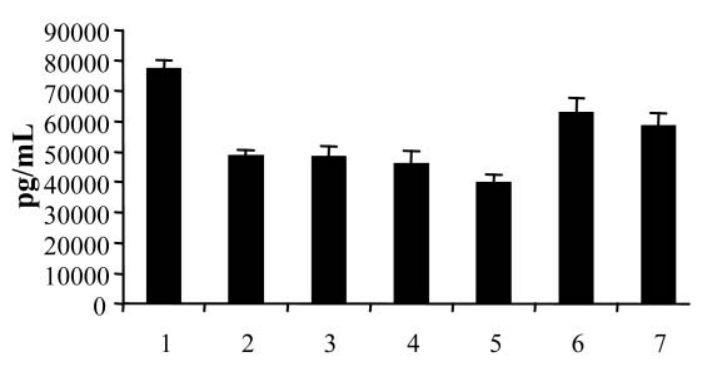

B

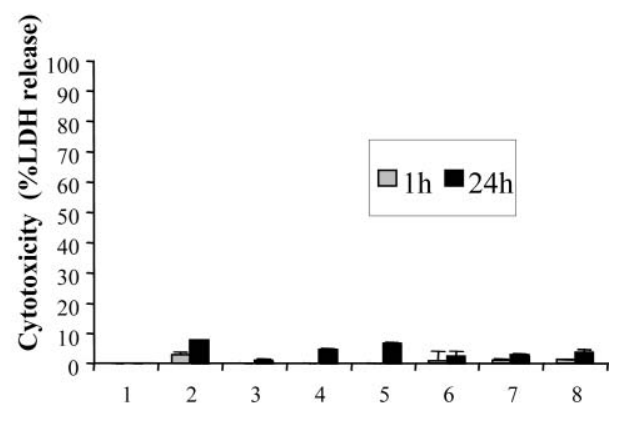

D

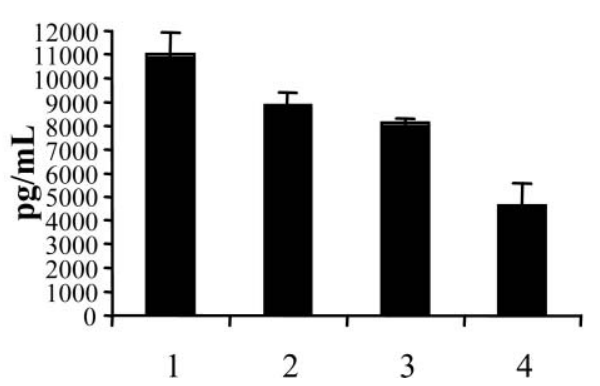

Fig. 10 (A) ELISA assay for p24 antigen release in MT-2 cells after $24 \mathrm{~h}$ incubation with dendriplexes. (B) The corresponding LDH cytotoxicity assay after 1 and 24 h. For A and B: (1) control; (2) dextran; (3) TAR; (4) 4-TAR; (5) cocktail 1; (6) 4-(cocktail 1); (7) cocktail 2; (8) 4-(cocktail 2). (C) and (D) ELISA assay for p24 antigen release in PBMCs after $24 \mathrm{~h}$ incubation with dendriplexes. (C) (1) Control; (2) TAR; (3) TARs; (4) random; (5) 3-TAR; (6) 3-TARs; (7) 3-random. (D) (1) Control; (2) dextran; (3) cocktail 1; (4) 4-(cocktail 1). Cocktails were an equimolecular mix of TAR + GEM91 (cocktail 1) or TAR + REV (cocktail 2) of final concentration $0.5 \mu \mathrm{M}$.

the corresponding dendriplexes suggest some degree of specificity when the dendrimer is present.

\section{Conclusion}

In conclusion, when ODNs form complexes with the carbosilane dendrimers, the nucleic acid material is protected from binding to proteins. Such protection could provide a meaningful advance for therapies based on short nucleic acids. This could translate into a reduction in the dose of ODN necessary to achieve the biological effect. When a naked ODN is administered, it is necessary to saturate all the possible binding sites within serum proteins to have a fraction of free ODN able to reach the extravascular space and perform the desired activity. If these interactions could be prevented by the formation of a complex of ODNs with a carbosilane dendrimer, presumably the saturation of binding sites would no longer be necessary, resulting in the possibility of administering smaller amounts of ODN. In addition, this could reduce the toxic effects related to these unspecific unions of the ODN to serum proteins. The toxicity measurements of the dendrimers and the transfection of nucleic material using the corresponding dendriplexes cultured in the presence of serum show no alteration of such processes. The HIV inhibition assays, also in the presence of serum, show an increase of $25-50 \%$ on going from naked ODN to the corresponding dendriplex as evidence of the protective effect mentioned above. Therefore, the carbosilane dendrimers presented here are good candidates as carriers in the context of biological applications of short nucleic acids and perhaps even other anionic drugs.

\section{Experimental}

\section{Dendrimers and ODNs synthesis}

Dendrimers 1-3 were prepared according to reported methods. ${ }^{15}$ Oligonucleotides were purchased from Eurogentec S.A. (Belgium). The ODNs sequences correspond to antisense (complementary) sequences of different HIV mRNAs: the HIV polypurine tract (PPT) element mRNA 5'-fluoresceine-TTT TCT TTT GGG GGG 3', 15 bases; TAR 5'-GCT CCC GGG CTC GAC C-3', 16 bases; GEM 91 5'-CTC TCG CAC CCA TCT CTC TCC TTC T-3', 25 bases; REV 5'-TCG TCG CTG TCT CCG CTT CTT CCT GCC A-3', 28 bases. TARs (sense) 5'-GGT CGA GCC CGG GAG C3', 15 bases. Random 5'-GCC TCA CGC GCG CTC-3', 15 bases. Cocktails were a mix of TAR + GEM91 (cocktail 1) or TAR + REV (cocktail 2).

Synthesis of 2G-[Si $\left.\left\{\mathrm{O}\left(\mathrm{CH}_{2}\right)_{2} \mathrm{~N}(\mathrm{Me})_{2}{ }^{+}\left(\mathrm{CH}_{2}\right)_{2} \mathrm{NMe}_{3}{ }^{+}\left(\mathrm{I}^{-}\right)_{2}\right\}\right]_{8}$ (4). Over a diethyl ether $(10 \mathrm{~mL})$ solution of $2 \mathrm{G}-\left[\mathrm{Si}\left\{\mathrm{O}\left(\mathrm{CH}_{2}\right)_{2} \mathrm{~N}\right.\right.$ (Me) $\left.\left.\left(\mathrm{CH}_{2}\right)_{2} \mathrm{NMe}_{2}\right\}\right]_{8}{ }^{15}(0.11 \mathrm{~g}, 0.04 \mathrm{mmol})$, a large excess of MeI $(0.06 \mathrm{~mL}, 0.91 \mathrm{mmol})$ was added. The resulting solution was stirred for $48 \mathrm{~h}$ at room temperature and then evaporated under reduced pressure to remove residual MeI. The residue was washed with $\mathrm{Et}_{2} \mathrm{O}(2 \times 5 \mathrm{~mL})$ and dried under vacuum to give $\mathbf{4}$ as a white solid 
(0.18 g, 86\%). ${ }^{1} \mathrm{H}$ NMR (DMSO): $\delta=4.00\left(16 \mathrm{H}, \mathrm{t}, \mathrm{OCH}_{2}\right), 3.93$ $\left(32 \mathrm{H}, \mathrm{m}, \mathrm{CH}_{2} \mathrm{~N}\left(\mathrm{Me}_{2}\right)^{+}\right), 3.59\left(16 \mathrm{H}, \mathrm{t}, \mathrm{CH}_{2} \mathrm{~N}(\mathrm{Me})_{3}{ }^{+}\right), 3.21(120 \mathrm{H}, \mathrm{s}$ br, $\mathrm{N}(\mathrm{Me})_{2}{ }^{+}$and $\left.\mathrm{N}(\mathrm{Me})_{3}{ }^{+}\right), 1.35\left(24 \mathrm{H}, \mathrm{m}, \mathrm{SiCH}_{2} \mathrm{CH}_{2} \mathrm{CH}_{2} \mathrm{SiO}\right.$ and $\left.\mathrm{SiCH}_{2} \mathrm{CH}_{2} \mathrm{CH}_{2} \mathrm{Si}\right), 0.72\left(16 \mathrm{H}, \mathrm{m}, \mathrm{SiCH}_{2} \mathrm{CH}_{2} \mathrm{CH}_{2} \mathrm{SiO}\right), 0.56(32 \mathrm{H}$, $\mathrm{m}$, rest of the groups $\left.-\mathrm{CH}_{2} \mathrm{Si}\right), 0.13\left(48 \mathrm{H}, \mathrm{s}, \mathrm{OSiMe}_{2}\right),-0.07$ $(12 \mathrm{H}, \mathrm{s}, \mathrm{SiMe}) ;{ }^{13} \mathrm{C}$ NMR (DMSO): $\delta=64.7\left(\mathrm{OCH}_{2}\right), 56.3$, 56.0, $55.7\left(\mathrm{CH}_{2} \mathrm{~N}\left(\mathrm{Me}_{2}\right)^{+}\right.$and $\left.\mathrm{CH}_{2} \mathrm{~N}(\mathrm{Me})_{3}{ }^{+}\right), 52.6\left(\mathrm{NMe}_{3}{ }^{+}\right), 50.9$ $\left(\mathrm{NMe}_{2}{ }^{+}\right), 21.2-17.2$ (groups $-\mathrm{CH}_{2}-$ of the carbosilane skeleton), $-2.5\left(\mathrm{OSiMe}_{2}\right),-5.5(\mathrm{SiMe})$. Elemental analysis calcd (\%) for $\mathrm{C}_{128} \mathrm{H}_{316} \mathrm{I}_{16} \mathrm{~N}_{16} \mathrm{O}_{8} \mathrm{Si}_{13}: \mathrm{C}, 33.40 ; \mathrm{H}, 6.92 ; \mathrm{N}, 4.87$; found: $\mathrm{C}, 32.90$; $\mathrm{H}, 6.75 ; \mathrm{N}, 4.57$.

\section{Electrophoresis measurements}

(i) Formation of dendrimer-ODN complexes (dendriplexes): complex formation between dendrimers and ODNs was carried out using an electrostatic approach. Mixtures were achieved with an excess of positive charge to provide enough positive charges to be able to interact with the ODN. Consequently, dendrimers 1-4 were complexed with ODNs at an electrostatic charge ratio (+)$(-)$ of $2: 1$. Ratios of ODN to dendrimer were based on the calculation of the electrostatic charge present on each component, e.g. the number of $\mathrm{S}^{-}$groups in the ODN vs. the number of terminal ammonium groups on the dendrimer. As an example, ODN and dendrimer 3 were diluted in sterile distilled water at 1 and $2 \mathrm{mg} \mathrm{mL}^{-1}$ respectively. $2.43 \mu \mathrm{l}$ of ODN solution were mixed with $3.25 \mu$ l of 3 solution in RPMI medium at a final volume of $60 \mu \mathrm{l}$, with an incubation time of 20 minutes at room temperature. After this period of incubation, parts of the mixtures of dendrimer-ODN were further exposed to increasing concentrations of $\mathrm{AB}$ human serum in a final volume of $100 \mu \mathrm{l}$ of RPMI medium (5\%, 10\%, 20\%). (ii) Evaluation of dendrimer-ODN complex formation and stability: after incubation of dendrimer and ODN in the presence or absence of human AB serum, complex formation and stability were assessed by evaluation of migration retardation of fluoresceinated ODNs during electrophoresis of dendriplexes on $3 \%$ agarose gels. A $100 \mathrm{bp}$ DNA ladder was used as reference (Gibco BRL ${ }^{\mathrm{TM}}$ ). Fluorescein enhances the ODN signal markedly, facilitating the visualization of dendriplex migration during electrophoresis. Additionally, the gel was polymerized in the presence of ethidium bromide (EB) in order to make more evident the ODN migration. (iii) Protein staining: after electrophoresis was performed, a digital photo of the gel stained with EB was taken; the same gel was later stained to evidence the protein migration by treatment with Blue Paragon (Beckmann Coulter ${ }^{\mathrm{TM}}$ ) protein staining. Finally, the gel was washed by immersion in a solution of $10 \%$ glacial acetic acid and a second digital photo was taken.

\section{Spectrofluorimetric measurements}

Fluorescent measurements were carried out with a Perkin-Elmer LS-50B spectrofluorometer. The excitation and emission wavelengths were 485 and $516 \mathrm{~nm}$ for ODNs labelled with fluorescein; 295 and $350 \mathrm{~nm}$ for BSA intrinsic fluorescence measurements; and 487 and $520 \mathrm{~nm}$ in the case of BSA labelled with Alexa Fluor 488 (AF488). The excitation and emission slit widths were set to 10 and $5 \mathrm{~nm}$, respectively. Changes in the steady-state fluorescence polarization were monitored for fluorescein that was a label in
ODN. Additionally, the intensity of intrinsic fluorescence of BSA and the intensity of the probe AF488 that was covalently attached to BSA were measured.

\section{Cells}

PBMCs cells were derived from healthy voluntary donors, and obtained from leukophoresed blood by Ficoll ${ }^{\mathrm{TM}}$ gradient and elutriation centrifugation. Prior to investigation with dendrimers, PBMCs were stimulated for $48 \mathrm{~h}$ with phytohemagglutinin $\left(2 \mu \mathrm{g} \mathrm{mL}^{-1}\right)$ and interleukin 2 (IL-2, $\left.100 \mathrm{IU} \mathrm{mL}^{-1}\right)$. On the day of the investigation, PBMCs were recovered and washed with phosphate buffered saline (PBS), and then seeded in RPMI 1640 (Gibco) medium supplemented with $10 \%$ of fetal calf serum, $1 \% \mathrm{~L}$-glutamine, antibiotics, and $50 \mathrm{IU} \mathrm{mL} \mathrm{mL}^{-1}$ of IL-2, in a $5 \%$ $\mathrm{CO}_{2}$ environment and $95 \% \mathrm{r}$. h. (relative humidity) (100 000 cells per well in 96-well plates for the toxicity curve of dendrimer concentrations). The final volume in each well was $200 \mu \mathrm{L}$ for the 96 -well plates and $500 \mu \mathrm{L}$ for the 24 -well plates. MT- 2 is a cell line transformed by human T-cell leukemia virus type 1 (HTLV-1) and cells were seeded in the same conditions as PBMCs.

\section{MTT (3-(4,5-dimethylthiazol-2-yl)-2,5-diphenyl tetrazolium bromide) assay}

This method was selected to analyze detrimental intracellular effects on mitochondria and metabolic activity. After 18 and $36 \mathrm{~h}$ of incubation of PBMCs with different concentrations of dendrimers in a 96-well plate, culture medium containing the dendrimers was replaced with $200 \mu \mathrm{L}$ of serum-free Optimem. $20 \mu \mathrm{L}$ of sterile filtered MTT (Sigma) stock solution in PBS $\mathrm{pH} 7.4\left(5 \mathrm{mg} \mathrm{mL}^{-1}\right)$ were added to each well to achieve a final concentration of $0.5 \mathrm{mg} \mathrm{MTT} \mathrm{mL} \mathrm{m}^{-1}$. After $4 \mathrm{~h}$, unreacted dye was removed by aspiration and the formazan crystals were dissolved in dimethyl sulfoxide (200 $\mu \mathrm{L}$ per well) (Sigma). The concentration of formazan was then determined spectrophotometrically in a plate reader (Biowhittaker microplate reader 2001, Innogenetics ${ }^{\circledR}$ ) at a wavelength of $550 \mathrm{~nm}$ (test) and $690 \mathrm{~nm}$ (reference). The spectrophotometer was calibrated to zero absorbance using Optimem medium without cells. The relative cell viability (\%) related to control wells (cells with no dendrimer) was calculated by $[A]$ test $/[A]$ control $\times 100$. Each dendrimer concentration was tested in triplicate, according to ATCC directives.

\section{Lactate dehydrogenase (LDH) assay}

The LDH concentration in these samples was assayed utilizing a commercial kit (Cytotoxicity Detection Kit, Roche), allowing the spectrophotometric determination of the nicotinamide adenine dinucleotide (NAD) reduction at $490 \mathrm{~nm}$ in the presence of lactate and LDH according to the manufacturer's protocol. After 1 and $24 \mathrm{~h}$ of incubation of cells with different concentrations of dendrimers in a 96-well plate, the supernatant was recovered. Controls were performed with $0.1 \%(\mathrm{w} / \mathrm{v})$ Triton X-100 and set as $100 \% \mathrm{LDH}$ release. The relative $\mathrm{LDH}$ release is defined by the ratio of $\mathrm{LDH}$ released over total $\mathrm{LDH}$ in the intact cells. Less than $10 \% \mathrm{LDH}$ release was regarded as a non-toxic effect level in our experiments. All samples were run in triplicate. 


\section{Confocal microscopy}

Cells for fluorescence microscopy were treated with $0.8 \%$ Trypan Blue $\left(\right.$ Sigma $\left.^{\mathrm{TM}}\right)$ for $5 \mathrm{~min}$ and then again washed twice with PBS. TB positive cells exhibited membrane damage. In addition, $\mathrm{TB}$ is an extra-cellular fluorescence quenching agent. After TB staining, cells were seeded on glass slides coated with poly-L-lysine, fixed with $3 \%$ paraformaldehyde, and labelled with a primary antiCD45 purified mouse anti-human monoclonal antibody (Becton Dickinson $^{\mathrm{TM}}$ ). Samples were washed twice with PBS and then incubated with a secondary antibody labelled in red (Texas Red dye-conjugated AffiniPure F (ab) ${ }_{2}$ fragment goat anti-mouse $\operatorname{IgG}+\operatorname{IgM}(\mathrm{H}+\mathrm{L})$, Jackson ImmunoResearch $\left.{ }^{\mathrm{TM}}\right)$. Cells were washed again twice with PBS. Finally, cells were treated for nuclear staining with 4',6'-diamidino-2-phenylindole (DAPI, Vysys ${ }^{\mathrm{TM}}$ ) for 10 min and washed three times with PBS. Samples were mounted and images captured by a Leica TCS SP2 confocal microscope using different lines of excitation: 405, 488 and $514 \mathrm{~nm}$.

\section{Enzyme immunoassay}

The ODN concentration for complexes with carbosilane dendrimers was $0.5 \mu \mathrm{M}(1.27 \mu \mathrm{g})$. The concentrations of the dendrimers were approximately $1 \mu \mathrm{M}$ for ODN alone, and $2 \mu \mathrm{M}$ when complexed with cocktails (final concentration in well). All complexes were formed in $50 \mu \mathrm{L}$ of PBS, with an incubation time of $20 \mathrm{~min}$ at room temperature. Cells were infected at 0.05 multiplicity of infection (MOI) with HIV isolate NL4-3 for $2 \mathrm{~h}$. Then, cells were washed twice and maintained in the same culture medium as above, supplemented with IL-2 (50 $\left.\mathrm{U} \mathrm{mL}^{-1}\right)$ (300 000 cells per well in 24well plates). The final volume for each well was $500 \mu \mathrm{L}$. ODN alone and complexed with dendrimer were added to the wells. The supernatant was collected at $24 \mathrm{~h}$ to evaluate antigen p24 by INNOTEST ${ }^{\mathrm{TM}}$ HIV antigen mAB (Innogenetics ${ }^{\circledR}$ ). Dextran sulfate was purchased from Sigma (USA) and it was used as a macromolecule control (polycation).

\section{Acknowledgements}

We thank the Ministerio de Ciencia y Tecnología (project CTQ2005-00795/BQU), the Plan Nacional de Salud (grant SAF2004-06778, SAF-2003-09209), Red temática de Investigación Cooperativa Sanitaria ISCIII (RED RIS RD06/0006), Fundación Caja Navarra, FIPSE (36514/05), the Dirección General de Investigación Científica y Técnica (grant BQU2004-02048), and Fundació LA CAIXA (BM04-52-0) for financial support. J. F. B.-M. is supported by a grant of Fondos de Investigación Sanitaria (CD05/00153). Dr Dzmitry Shcharbin is a beneficiary of a Marie Curie International Incoming Fellowship within the 6th EU Framework Programme (grant 510018). We also want to thank R. Samaniego for help with confocal microscope image analysis and to N. Weber for corrections with the English in the paper.

\section{References}

1 L. Belmonte, P. Bare, M. M. De Bracco and B. H. Ruibal-Ares, Curr. Med. Chem., 2003, 10, 303-312.

2 S. Hacein-Bey-Abina, C. von Kalle, M. Schmidt, F. Le Deist, N. Wulffraat, E. McIntyre, I. Radford, J. L. Villeval, C. C. Fraser, M. Cavazzana-Calvo and A. Fischer, N. Engl. J. Med., 2003, 348, 255-256.

3 (a) S. K. Srinivasan, H. K. Tewary and P. L. Iversen, Antisense Res. Dev., 1995, 5, 131-139; (b) S. P. Henry, W. Novotny, J. Leeds, C. Auletta and D. J. Kornbrust, Antisense Nucleic Acid Drug Dev., 1997, 7, 503 510; (c) E. Rayburn, W. Wang, R. Zhang and H. Wang, Prog. Drug Res., 2005, 63, 227-274.

4 (a) D. A. Geselowitz and L. M. Neckers, Antisense Res. Dev., 1995, 5, 213-217; (b) M. H. Fabani, J. J. Turner and M. J. Gait, Curr. Opin. Mol. Ther., 2006, 8, 108-114.

5 (a) P. Hawley and I. Gibson, Antisense Nucleic Acid Drug Dev., 1996, 6, 185-195; (b) Y. Nakta, T. K. Kim, S. Shtezline and A. M. Gewitz, Crit. Rev. Eukaryotic Gene Expression, 2005, 15, 163-182.

6 S. Zhang, Y. Xu, B. Wang, W. Qiao, D. Liu and Z. Li, J. Controlled Release, 2004, 100, 165-180.

7 (a) S. M. Grayson and J. M. J. Fréchet, Chem. Rev., 2001, 101, 38193867; (b) S. E. Stiriba, H. Frey and R. Haag, Angew. Chem., 2002, 114, 1385-1390, (Angew. Chem., Int. Ed., 2002, 41, 1329-1334); (c) U. Boas and P. M. H. Heegaard, Chem. Soc. Rev., 2004, 33, 43-63.

8 (a) T. Hernández-Caselles, J. Villalain and J. C. Gómez-Fernández, Mol. Cell. Biochem., 1993, 120, 119-126; (b) J. P. Yang and L. Huang, Gene Ther., 1997, 4, 950-960; (c) C. Tros de Ilarduya and N. Düzgünes, Biochim. Biophys. Acta, 2000, 1463, 333-342.

9 G. McLachlan, B. J. Stevenson, D. J. Davidson and D. J. Porteous, Gene Ther., 2000, 7, 384-392.

10 H. Yoo, P. Sazani and R. L. Juliano, Pharm. Res., 1999, 16, 1799-1804.

11 (a) M. Maszewska, J. Leclaire, M. Cieslak, B. Nawrot, A. Okruszek, A. M. Caminade and J.-P. Majoral, Oligonucleotide, 2003, 13, 193205; (b) C. Loup, M. A. Zanta, A.-M. Caminade, J.-P. Majoral and B. Meunier, Chem.-Eur. J., 1999, 5, 3644-3650; (c) A. V. Maksimenko, V. Mandrouguine, M. B. Gottikh, J. R. Bertrand, J.-P. Majoral and C. Malvy, J. Gene Med., 2003, 5, 61-71.

12 D. Joester, M. Losson, R. Pugin, H. Heinzelmann, E. Walter, H. P. Merkle and F. Diederich, Angew. Chem., 2003, 115, 1524-1528, (Angew. Chem., Int. Ed., 2003, 42, 1486-1490).

13 For some examples see: (a) B. Klajnert and M. Bryszewska, Bioelectrochemistry, 2002, 55, 33-55; (b) B. Klajnert, L. Stanislawska, M. Bryszewska and B. Palecz, Biochim. Biophys. Acta, 2003, 1648, 115126; (c) T. Chiba, T. Yoshimura and K. Esumi, Colloids Surf., A, 2003, 214, $157-165$.

14 J. Roesnecker, S. Naundorf, S. W. Gersting, R. W. Hauck, A. Gessner, P. Nicklaus, R. H. Muller and C. Rudolph, J. Gene Med., 2003, 5, 49-60.

15 (a) P. Ortega, J. F. Bermejo, L. Chonco, E. de Jesús, F. J. de la Mata, G. Fernández, J. C. Flores, R. Gómez, M J. Serramía and M A. MuñozFernández, Eur. J. Inorg. Chem., 2006, 7, 1388-1396; (b) J. F. Bermejo, P. Ortega, L. Chonco, R. Eritja, R. Samaniego, M. Müller, E. de Jesús, F. J. de la Mata, J. C. Flores, R. Gómez and M A. Muñoz-Fernández, Chem.-Eur. J., 2007, 13, 483-495.

16 M. F. Ottaviani, S. Jockusch, N. J. Turro, D. A. Tomalia and A. Barbon, Langmuir, 2004, 20, 10238-10245.

17 V. Dapic, V. Abdomerovic, R. Marrington, J. Peberdy, A. Rodger, J. O. Trent and P. J. Bates, Nucleic Acids Res., 2003, 31, 2097-2107.

18 D. Shcharbin, E. Pedziwiatr, L. Chonco, J. F. Bermejo-Martín, P. Ortega, F. J. de la Mata, R. Eritja, R. Gómez, B. Klajnert, M. Bryszewska and M. A. Muñoz-Fernandez, Biomacromolecules, submitted.

19 (a) C. Lavigne, J. Yelle, G. Sauvé and A. R. Thierry, AAPS PharmSci, 2002, 4(2), article 9 (http://www.aapspharmsci.org); (b) J. F. Bermejo, L. Chonco, R. Samaniego, G. Fernández, R. Eritja and M. A. MuñozFernández, Eur. J. Sci. Res., 2006, 15, 113-121. 